Bond University

Research Repository

\title{
Employee perceptions of organization culture with respect to fraud - where to look and what to look for
}

Kumar, Kuldeep; Bhattacharya, Sukanto; Hicks, Richard E.

Published in:

Pacific Accounting Review

DOI:

10.1108/PAR-05-2017-0033

Link to output in Bond University research repository.

Recommended citation(APA):

Kumar, K., Bhattacharya, S., \& Hicks, R. E. (2018). Employee perceptions of organization culture with respect to fraud - where to look and what to look for. Pacific Accounting Review, 30(2), 187-198.

https://doi.org/10.1108/PAR-05-2017-0033

\section{General rights}

Copyright and moral rights for the publications made accessible in the public portal are retained by the authors and/or other copyright owners and it is a condition of accessing publications that users recognise and abide by the legal requirements associated with these rights.

For more information, or if you believe that this document breaches copyright, please contact the Bond University research repository coordinator. 


\section{Employee perceptions of organization culture with respect to fraud - where to look and what to look for}

\section{Structured Abstract}

Purpose: Recent research has confirmed an underlying economic logic that connects each of the three vertices of the "fraud triangle" - a fundamental criminological model of factors driving occupational fraud. It is postulated that in the presence of economic motivation and opportunity (the first two vertices of the fraud triangle), the likelihood of an occupational fraud happening in an organization increases substantially if the overall organization culture is perceived as being slack towards fraud as it helps potential fraudsters in rationalizing their actions (rationalization being the third vertex of the fraud triangle).This paper offers a viable approach for collecting and processing of data in order to identify and operationalise the key factors underlying employee perception of organization culture towards occupational frauds.

Design/methodology/approach: This paper reports and analyses the results of a pilot study conducted using a convenience sampling approach to identify and operationalise the key factors underlying employee perception of organization culture with respect to occupational frauds. Given a very small sample size, a numerical testing technique based on the binomial distribution has been applied to test for significance of the proportion of respondents who agree that a lenient organizational culture towards fraud can create a rationalization for fraud.

Findings: The null hypothesis assumed no difference in the population proportions between those who agree and those who disagree with the view that a lenient organizational culture towards fraud can create a rationalization for fraud. Based on the results of the numerical test, the null hypothesis is rejected in favour of the alternative that the population proportion of those who agree with the stated view in fact exceeded the proportion of those who disagreed.

Research limitations/implications: The obvious limitation is the very small size of the sample obtained due to an extremely low rate of response to the survey questionnaires. However, while of course a much bigger data set needs to be collected in order to develop a generalizable prediction model, the small sample was enough for the purpose of a pilot study.

Practical implications: This paper makes two distinct practical contributions. Firstly, it posits a viable empirical research plan for identifying, collecting and processing the right data to identify and operationalise the key underlying factors that capture an employee's perception of organizational culture towards fraud as a basis for rationalizing an act of fraud. Secondly, it demonstrates via a small-scale pilot study, that a more broad-based survey can indeed prove to be extremely useful in collating the sort of data that is needed to develop a computational model for predicting the likelihood of occupational fraud in any organization.

Originality/value: This paper provides a viable framework which empirical researchers can follow in order to test some of the latest advances in the "fraud triangle" theory. It outlines a systematic and focused data collection method via a well-designed questionnaire that is effectively applicable to future surveys that are scaled up to collect data at a nationwide level. 


\section{Introduction}

White collar crime has been seen as a problem for many years (Dorminey et al., 2012; Sutherland, 1949). One of the most prevalent white-collar crimes is occupational fraud, which is formally defined by the Association of Certified Fraud Examiners as "the use of one's occupation for personal enrichment through the deliberate misuse or misapplication of the employing organization's resources or assets” (ACFE, 2014).

ACFE reports have consistently revealed that a sizeable percentage of net revenues are lost by US businesses to occupational fraud every year. The Asia-Pacific region throws forth a similar picture. According to a survey conducted by KPMG, more than a hundred frauds occurred in Australia in 2015-16 with a value exceeding \$300 billion - an average value per fraud of more than \$3 million (KPMG, 2016). Yet the respondents to such surveys have often expressed the view that only a very small fraction of the total number of cases of fraud are being actually reported, which indicate that those being captured are no more than the tip of the iceberg.

Occupational fraud is increasingly being acknowledged as a major criminal threat to Australia's domestic socio-economic fabric. Contrary to common belief, it is not a "victimless" crime as it constitutes a substantial drain on a nation's productive resources. The cost has to be ultimately borne by someone and it is often the final consumers who bear the brunt of the economic costs. For example, with shoplifting, where businesses are victimized by criminal conduct of a few customers, the businesses typically pass on those costs to their other paying customers. With occupational fraud, the businesses are victimized by their own employees but much in the same way as with shoplifting, these costs are passed on to the final consumers. The main way to counter occupational fraud is to continuously improve the internal control systems of an organization (Rae and Subramaniam, 2008). The cost of continuous improvement should be more than offset by the benefits derived in the form of cost savings from reduced instances of occupational fraud.

The "fraud triangle" has been posited and developed by several researchers as the primary causative theory about the motivating elements behind occupational fraud (Dorminey et al., 2012). The theory emphasises motives-pressures (needs) of individuals at one corner of the triangle; and opportunity and rationalisation at the other two corners (Wilks and Zimbelman, 
2004). However, there has been no systematic study conducted as yet that fully uses the fraud triangle in order to develop a fraud prediction model that can assist regulatory policy-making.

To commit an act of occupational fraud, an employee must have a definite "motivation" that simulates him or her to act in such a way (Ajzen, 1991). If an employee perceives that he or she can enjoy a net positive economic gain by committing fraud and not getting caught then that knowledge can motivate the employee to commit the act. Of course, not every employee will commit an act of fraud against the employer just because there is potential for an economic gain and an opportunity to do so and not get caught. Most employees will successfully resist temptations to commit an act of fraud. However, some may fall prey to such temptations if both incentive and opportunity remain present in the organizations over a sustained time (Beck and Ajzen, 1991; Ajzen, 1991).

If, over time, an employer fails to remove the incentive and opportunity to commit fraud, a few employees may take this as a signal of "slack organizational culture" with respect to acts of occupational fraud and cause them to rationalise their actions by developing their belief that no one would care. As stated previously, "incentive” (otherwise identified as motivespressures), “opportunity” and "rationalization” are the three vertices of the fraud triangle. These three elements were first recognised by Sutherland (1949), and later developed by Cressey (1953). Comer (1977) subsequently analysed and further expanded on Cressey's initial theory. In the following decade, Albrecht et al. (1982) further honed the underlying criminological concept in identifying effective strategies for fraud detection. There is a relatively recent empirical study on the fraud triangle model that aimed to determine its efficacy in setting up stronger internal controls (Rae and Subramaniam, 2008).

However, loss due to systemic deficiency can also be attributed to fault rather than fraud. Deficiencies originating either from an erring individual or a poor quality-control environment can be the source of a fault (Ozkul and Pamukcu, 2012). There has been some data mining-based research that has aimed to differentiate statistically between "benign" and "fraudulent" manipulations in financial reporting data; where the "benign" manipulations are representative of faults rather than intentional fraud (Busta and Weinberg, 1998; Bhattacharya et al., 2011). However, the aim of this paper is to focus on the underlying drivers where it is clearly an intentional act. 
There is a disparate body of extant research on the drivers of criminal fraud - mostly within criminology and forensic psychology - but there is some also in the accounting and auditing literature. However, the existing literature is almost exclusively made of empirical research that is rather piecemeal in appearance. This is because till very recently, there was no overarching theoretical structure that could effectively bind the empirical research in a consistent and focused direction. Boulter, Mukherjee and Bhattacharya (2013) produced arguably the first theoretical structure by mathematically connecting the three vertices of the fraud triangle and positing a formal setup which can help to instil more focus within future empirical research.

This paper looks closely at some of the implications of the Boulter, Mukherjee and Bhattacharya (2013) (hereafter BMB) model and sets out a viable research plan for an empirical enquiry into the fraud triangle that would test the veracity of that model. This work is divided into three sections including this introductory section. The next section examines the fraud triangle in light of past research and also how the BMB (2013) model helps to combine all (or at least some of the major) past ideas about the fundamental nature of the fraud triangle into a unified theoretical edifice that is amenable to focused empirical enquiry. The third and final section concludes our paper by proposing a viable empirical research plan based on the findings from our pilot study.

\section{The "fraud triangle" - a short collation of ideas from past research}

An act of financial fraud is essentially an act of criminal deception (Allen et al., 2006). Internal as well as external audit mechanisms regularly incorporate the fraud triangle model by organizing and presenting fraud risk factors as per the vertices of the fraud triangle i.e. incentive, opportunity and rationalization (Albrecht et al., 1982; Loebbecke et al, 1989). It has been argued that such presentation will require less cognitive effort by auditors in assessing fraud risk and thereby help them to better process information (Wilks and Zimbelman, 2004). There have been a number of empirical research works that have aimed to determine, at some level of statistical significance, the efficacy of auditor training or the audit process itself when relevant information is organized and presented in line with the vertices of the fraud triangle. However, all of them have taken the fraud triangle as a given rather than looking deeper into what it entails and how, or even whether, the vertices are inter-linked. 
Dellaportas (2013) interviewed a number of professional accountants serving prison time with financial fraud convictions. While his study provides arguably one of the strongest empirical appraisals of the veracity of the fraud triangle in explaining fraud, it still doesn't help put forward a unified theory of fraud that can be subsequently used to derive a predictive model to compute the likelihood of fraud occurrence. Lou and Wang (2009) did construct a predictive model based on examples of fraud risk factors in line with the fraud triangle vertices to gauge the likelihood of occurrence of a financial reporting fraud. However, their work neither delves into the details of what each of the vertices actually entails nor empirically investigates any interlinkages between the vertices.

There have been some other data mining-based research approaches that have tried to build a predictive model of occupational fraud using the fraud triangle set-up (e.g. Fanning and Cogger 1998; Kim and Kwon, 2006; Kirkos et al., 2007 and Jans et al., 2010). However, as their methodologies indicate, these were primarily data mining studies that posited no theory.

Davis and Pesch (2013) proposed an agent-based theory of organizational fraud. In their model, individual heterogeneous "agents" who could have a motive and an opportunity as well as an attitude to commit fraud were allowed to interact with one another in a dynamic set-up. Their model shows how a process of cultural transmission shapes attitudes towards fraud and is an important theoretical addition to the fraud triangle literature. However, it again assumes the fraud triangle as a given and doesn't help explain how the vertices actually come about.

There have also been some extensions to the classical fraud triangle theory of Sutherland (1949) and Cressey (1953). For example, Albrecht et al. (2004) postulated the "broken trust" theory drawing from the agency hypothesis of corporate finance literature while Choo and Tan (2007) drew from sociological theory to posit an "American dream” theory of executive fraud. However, these extensions, similar to most others in the field, are largely limited to anecdotal evidence gathering in support of a pre-existing notion; albeit dressed in a new garb.

BMB (2013) posited a formal mathematical model of the fraud triangle that drew from economic theory to postulate a set of relationships between each of the three vertices. According to the "expectancy theory of motivation", (Vroom, 1964; Porter and Lawler, 1968), workplace motivation is driven by "valence"; defined as the product of the magnitude of the reward at stake and the probability of actually reaping the reward as deemed by the 
individual employee. BMB (2013) defined “net valence” as the difference between valence and "counter valence" which represents the forces that negate or counteract valence. They derived a mathematical expression of "net valence" for an employee from an act of occupational fraud and went on to demonstrate that this is zero in a condition of equilibrium where the valence (or motivation to commit) fraud is exactly offset by counter valence (or motivation not to commit) fraud. This balance depends critically on the availability of opportunity to commit and get away with fraud (or at least the employee's perception of such opportunity). Both the balance between valence and counter-valence and perception of opportunity in turn were shown in the BMB (2013) model to critically depend on the rationalization for an act of fraud. This has offered a mathematical explanation of the fraud triangle in terms of the inter-relations between each of the three vertices, thus opening up the theory to empirical testing. The most significant implication of the BMB (2013) model was the primacy of the organizational culture towards fraud as the ultimate driver of occupational fraud committed by an employee. This is mathematically derived in the model as a ratio that takes the following algebraic form:

$$
c / r=p /(1-q)
$$

BMB (2013) defines $c$ as the "personal cost" to the employee of getting caught after committing a fraud while $r$ is defined as the "personal gain" to the employee from an act of fraud if he or she gets away with it. That is, $\mathrm{c} / \mathrm{r}$ is essentially interpretable as the risk-toreward ratio for an act of fraud to an individual employee, while $p$ and $q$ are organizational attributes. Specifically $p$ is the likelihood of the perceived organization culture towards fraud changing from "strict" to "slack" over a finite time length while $q$ is the likelihood of the organization culture towards fraud not changing at all, given that it is currently perceived as "slack". This derivation of course entails some simplifying assumptions in order to ensure mathematical tractability but the main finding of the model is nonetheless shown to be satisfactorily robust.

The BMB (2013) model demonstrates that the equilibrium $c / r$ value is linear in $p$ but exponential in $q$. This implies that the scope for rationalizing an act of occupational fraud by an individual employee against the employing organization is most sensitive to whether he or she perceives the current organizational culture towards occupational fraud to be "slack", and also the perceived notion of the culture continuing to be a "slack" one in the foreseeable 
future. The earlier work of Davis and Pesh (2012) in particular on the process of cultural transmission of attitude towards fraud within an organization lends additional credence to the theoretical model findings of BMB (2013). However, what is now required is a full-on empirical enquiry into the role of organizational culture (more importantly; that which is perceived by employees of the organization) in determining the likelihood of a random employee falling victim to temptations if an incentive and an opportunity were both to be suddenly presented.

That organizational culture can play a crucial role in shaping employee attitudes towards fraud has been identified in several earlier studies (Holton, 2009; Pfister, 2009; Davis and Pesch, 2013). However, any effort to systematically unravel the role of organizational culture in affecting (either increasing or decreasing) the likelihood of occurrence of occupational fraud in an organization is an area that has received little research attention till now. While

several researchers seem to agree on a definite role played by organizational culture, the extant literature on occupational fraud research is lacking in this regard mainly for logistical reasons. Any productive research on the relationship between organizational culture and likelihood of occupational fraud will have to involve a strongly multi-disciplinary team. Sadly, it is not common for behavioural scientists, accounting/finance experts and data analysts to join hands and form the sort of interdisciplinary team required for such a venture.

In the concluding section we posit an interdisciplinary research plan along with some preliminary results that we believe will be effective in empirically testing the BMB (2013) model of the fraud triangle and also, more importantly, help in deriving a predictive tool to determine the likelihood of occurrence of occupational fraud in an organization in the immediate future.

\section{Determining the drivers of occupational fraud - an empirical research plan}

The fraud triangle may explain occupational fraud - but what explains the fraud triangle? So far most research on the fraud triangle has taken it as a given without delving into the constituents of each of the three vertices, that is, giving general weightings to the vertices instead of the alternative we are espousing, of giving detailed attention and weightings to the factors that contribute to each vertex. The BMB (2013) model has produced a theoretical underpinning for the vertices that can now be subjected to a more focused empirical enquiry. Specifically one would want to identify the key individual as well as organizational factors 
that underlie each of the three vertices to ascertain their relative roles in shaping perceptions. The first challenge is of course to identify the factors and the second, more difficult challenge is to operationalise all those factors into quantitative variables to be embedded into a model to test the significance of an employee's perception of organizational culture as a key driver.

Therefore, in terms of a systematic research methodology, the primary focus should be on identifying the core concepts underlying each of the three fraud triangle vertices that should be clearly targeted perhaps in an exploratory survey, with an objective of gleaning information that will be useful in their effective operationalization. The "incentive" vertex, being primarily a financial construct, may be effectively operationalised via information on what are the organizational assets that have the highest fraud risk exposure - that is, which assets would be the first ones to be misappropriated by an employee or group of employees with criminal intent if the weakest link in the internal control chain broke. As per intuitive economic logic (Boulter, Mukherjee and Bhattacharya, 2013), the “opportunity” vertex may be effectively operationalised via information on both the current status of internal controls, how they compare amongst similar organizations and also future planned reviews or upgrades in light of presently identified loopholes and weaknesses. The "rationalization” vertex may be assessed based on exhaustive meta-analytical searches and other research on related behavioural variables such as "integrity" and "conscientiousness" (e.g., Kaiser and Hogan, 2010; Van Iddekinge et al., 2012) as well as semi-structured interviews with a selected panel of subject matter experts from both academia and industry. Interviewing a stratified random sample of financial controllers as well as a cross-section of employees at different levels of seniority in various corporate organizations could then be used to cross-identify the behavioural drivers thought to be the main contributors. The first step would be the development of a comprehensive survey instrument that could be employed in a nationallevel survey to elicit responses from financial controllers as well as a cross-section of employees in corporate organizations of varying sizes ranging across different industries. In developing the survey instrument a measure of the relationships of the items and factors to the criterion variables will of course have to be closely examined as a partial move towards their subsequent validation, followed by more in-depth validations by investigating the cogency of those variables against available concurrent and relevant criterion data. Subsequently, the information gleaned from the survey responses, after required filtering and processing, should yield the raw data for a predictive model of occupational fraud likelihood. 
We present below the statistical analysis results from a small sample survey of industry experts on financial fraud conducted as a preliminary pilot study to elicit initial information required to identify the key factors underlying each of the three vertices towards their subsequent operationalization and validation in a prediction model. The particular design of our pilot survey questionnaire is predicated on the findings of earlier studies we covered in our literature review that aimed to isolate the common factors underlying the decisionmaking process under each of the three fraud triangle vertices (e.g. Rae and Subramaniam, 2008; Özkul and Pamukçu, 2012; Dellaportas, 2013). However, it is important to note that our pilot study design is a simplified version of a more broad-based future survey. So, while the survey questionnaire did elicit inputs from the responders along several dimensions, this study only considers the responses particular to a single dimension - whether or not an organization culture that is seen to be lenient towards occupational fraud can help in rationalizing acts of fraud. A copy of the pilot survey questionnaire is given in the Appendix.

Thirteen responses were received making it an extremely small sample. While of course a much bigger data set needs to be collected for implementing the broad-based survey in order to develop a generalizable prediction model, a small sample can be used to run a pilot study. However, as the sample size was too small for a z-test for significance of population proportion, we applied a binomial method to conduct the test of significance for the population proportion. The binomial method is appropriate choice of methodology, given the very small sample size; and given the fact that if the responders were purely random in giving their opinion either in favour or against the stated view; then the then the proportions that agree and disagree will both tend to be exactly half. Out of the 13 respondents, 11 agreed with the stated view that a lenient organizational culture towards fraud can help to rationalise an act of occupational fraud thus yielding a sample proportion of 11/13.

We performed the following one-tailed test of hypothesis:

$\mathrm{H}_{0}: \rho=50 \%$, i.e. no difference in the population proportions of agreed versus disagreed $\mathrm{H}_{1}: \rho>50 \%$ i.e. a higher proportion of the population agreed with the stated view

Parameter of interest: population proportion $\rho$; of respondents who agree that a lenient/casual organizational culture towards fraud could potentially contribute towards rationalizing fraud. 
Test statistic: $x=$ number of respondents who are in agreement.

Rejection region for the null hypothesis: $x>\mathrm{k}$ for some particular value $\mathrm{k}$ in the range $(0,13)$.

$$
\operatorname{Prob}(\text { Type } \text { I error })=\operatorname{Prob}\left(\mathrm{H}_{0} \text { is rejected } \mid \mathrm{H}_{0} \text { is true }\right)=\operatorname{Prob}(x>\mathrm{k} \mid \rho=0.50)
$$

We generate the following binomial distribution $\mathrm{P}_{\mathrm{k}}$ such that:

$$
\mathrm{P}_{\mathrm{k}}={ }^{\mathrm{n}} \mathrm{C}_{\mathrm{k}} \rho^{\mathrm{k}}(1-\rho)^{(\mathrm{n}-\mathrm{k})}
$$

Here $\mathrm{n}=13, \rho=0.50, \mathrm{C}$ is the combinatorial operator and $\mathrm{k}$ is an integer ranging from 0 to 13 . The $\mathrm{P}_{\mathrm{k}}$ values for the series as well as the cumulative probability values are shown in Table 1:

Table 1: Binomial probability distribution for $\rho=0.50$ and $\mathrm{n}=13$

\begin{tabular}{|r|c|c|}
\hline $\begin{array}{c}\text { Count } \\
(\mathbf{k})\end{array}$ & $\begin{array}{c}\text { Prob. } \\
\left(\mathbf{P}_{\mathbf{k}}\right)\end{array}$ & $\begin{array}{c}\text { Cum. Prob. } \\
\left(\boldsymbol{\Sigma} \mathbf{P}_{\mathbf{k}}\right)\end{array}$ \\
\hline 0 & 0.0001 & 0.0001 \\
1 & 0.0016 & 0.0017 \\
2 & 0.0095 & 0.0112 \\
3 & 0.0349 & 0.0461 \\
4 & 0.0873 & 0.1334 \\
5 & 0.1571 & 0.2905 \\
6 & 0.2095 & 0.5000 \\
7 & 0.2095 & 0.7095 \\
8 & 0.1571 & 0.8666 \\
9 & 0.0873 & 0.9539 \\
10 & 0.0349 & 0.9888 \\
11 & 0.0095 & 0.9983 \\
12 & 0.0016 & 0.9999 \\
13 & 0.0001 & 1.0000 \\
\hline
\end{tabular}

From the cumulative probability values in Table 1, it can be seen that the cut-off for a $5 \%$ level of significance occurs between $k=8$ and $k=9$. This is because for $k=8,1-0.8666=$ 
$0.1334>5 \%$ while for $\mathrm{k}=9,1-0.9539=0.0461<5 \%$. This means that we can reject $\mathrm{H}_{0}$ at the $5 \%$ level of significance as our actual $k=11$. Moreover, for a $1 \%$ level of significance, the cut-off value has to occur somewhere between 10 and 11 . At 10 it is $1-0.9888=0.0112$ $>1 \%$ while at 11 it is $1-0.9983=0.0017<1 \%$; so $\mathrm{H}_{0}$ can in fact be rejected at the $1 \%$ level of significance given that our $\mathrm{k}=11$. However, note that while for the $5 \%$ cut-off level of $9, \mathrm{k}$ $=11$ has a cushion of 2 , for the $1 \%$ cut-off level this cushion is in fact less than 1 . This is an important consideration given the nearly unviable sample size i.e. we can state with a lot more conviction that $\mathrm{H}_{0}$ is rejected at the $5 \%$ level as compared to the $1 \%$ significance level.

\section{Conclusion and future research}

The preliminary results offer some indicative support to the BMB (2013) model by showing up the perceived leniency in the organizational culture towards fraud as a potentially important contributor towards rationalization of an act of fraud. The pilot study results justify the application of a similar study design on a larger scale (ideally at a national level) and the analysis of data acquired along multiple dimensions rather than only one as was done here. A future, expanded study should ideally also incorporate key variables identified and operationalised in disciplines like criminology and other related behavioural sciences to test the robustness of the model especially when input data are drawn from disparate sources. Another possible angle of future research would be to investigate whether a one-size-fits-all model is warranted or whether it might be better to develop industry-specific sub-models.

As noted in the proposed empirical research plan outlined earlier, the first step would be the development of a comprehensive survey instrument along lines of the questionnaire we have used here (copy provided in Appendix) but possibly even more broad-based to enhance data capture across multiple dimensions. A large sample would also afford other, more statistically robust data analysis techniques to be applied thereby leading to stronger validation of results. If done appropriately, a scaled-up future study along the lines we have conducted here can go a long way to appropriately identify and operationalise the key underlying factors that can then be fed into a computational model to measure the effect of perceived organization culture as a key driver of occupational fraud and how it can better predict fraud likelihood. 


\section{References}

ACFE Report to the Nations on Occupational Fraud and Abuse (2014), “2014 Global Fraud Study”. Association of Certified Fraud Examiners, www.acfe.com/rttn-introduction.aspx, last retrieved on $5^{\text {th }}$ May, 2017.

Allen, R. D., Hermanson, D. R. Kozloski, T. M. and Ramsay, R. J. (2006), “Auditor Risk Assessment: Insights from the Academic Literature”, Accounting Horizons, Vol. 20, No. 2, pp. 157-177.

Ajzen, I. (1991), “The Theory of Planned Behavior”, Organizational Behavior and Human Decision Processes, Vol. 50, pp. 179-211.

Albrecht, W. S., Romney, M. B., Cherrington, D. J., Payne, I. R. and Roe, A. J. (1982), How to Detect and Prevent Business Fraud, Prentice-Hall, Englewood Cliffs, NJ.

Albrecht, W. S., Albrecht, C. C. and Albrecht, C. O. (2004), "Fraud and corporate executives: Agency, Stewardship and Broken Trust”, Journal of Forensic Accounting, Vol. 5, pp. 109130.

Beck, L. and Ajzen, I. (1991), "Predicting Dishonest Actions using the Theory of Planned Behavior”, Journal of Research in Personality, Vol. 25, No. 3, pp. 285-301.

Bhattacharya, S., Xu, D. and Kumar, K. (2011), “An ANN-based auditor decision support system using Benford's law”, Decision Support Systems, Vol. 50, No. 3, pp. 576-584.

Boulter, T., Mukherjee, A. and Bhattacharya, S. (2013), "Motivation for Occupational Fraud: An Analysis of the "Fraud Triangle" Using Economic Logic", International Journal of Interdisciplinary Organizational Studies, Vol. 7, No. 1, pp. 47-56.

Busta, B. and Weinberg, R. (1998), “Using Benford's law and neural networks as a review procedure”, Managerial Auditing Journal, Vol. 13, No. 6, pp. 356-366.

Choo, F. and Tan, K. (2007), “An “American Dream” theory of corporate executive Fraud”, Accounting Forum, Vol. 31, No. 2, pp. 203-215.

Comer, M. J. (1977), Corporate Fraud. McGraw-Hill, London. 
Cressey, D. R. (1953), Other people's money; a study of the social psychology of embezzlement. Free Press, New York, NY.

Davis, J. S. and Pesch, H. L. (2013), "Fraud dynamics and controls in organizations" Accounting, Organizations and Society, Vol. 38, No. 6 - 7, pp. 469 - 483.

Dellaportas, S. (2013), “Conversations with inmate accountants: Motivation, opportunity and the fraud triangle”, Accounting Forum, Vol. 37, No. 1, pp. 29-39.

Dorminey, J., Scott Fleming, A, Kranacher, M-J. and Riley, R. A. Jr. (2012), “The Evolution of Fraud Theory”, Issues in Accounting Education, Vol. 27, No. 2, pp. 555-579.

Fanning, K. and Cogger, K. (1998), "Neural network detection of management fraud using published financial data”, International Journal of Intelligent Systems in Accounting, Finance and Management, Vol. 7, pp. 21-41.

Holton, C. (2009), “Identifying disgruntled employee systems fraud risk through text mining: A simple solution for a multi-billion dollar problem”, Decision Support Systems, Vol. 46, No. 4, pp. 853-864.

Jans, M. Lybaert, N. and Vanhoof, K. (2010), “Internal fraud risk reduction: Results of a data mining case study”, International Journal of Accounting Information Systems, Vol. 11, 1741.

Kaiser, R., and Hogan, R. (2010), "How to (and how not to) assess the integrity of managers”, Consulting Psychology Journal: Practice and Research, Vol. 62, No. 4, pp. 216234

Kim, H. and Kwon, W. J. (2006), "A multi-line insurance fraud recognition system: a government-led approach in Korea”, Risk Management and Insurance Review, Vol. 9, No. 2, pp. 131-147.

Kirkos, E., Spathis, C. and Manolopoulos, Y. (2007), "Data mining techniques for the detection of fraudulent financial statements”, Expert Systems with Applications, Vol. 32, pp. 995-1003. 
KPMG (2016), “Surge in number and value of frauds: KPMG survey”, KPMG Australia, https:/home.kpmg.com/au/en/home/media/press-releases/2016/06/fraud-barometer-showsrise-in-frauds-15-jun-2016.html, last retrieved on $5^{\text {th }}$ May, 2017.

Loebbecke, J. K., Eining, M. M. and Willingham, J. J. (1989), “Auditors’ Experience with material Irregularities: Frequency, Nature and Detectability”, Auditing: A Journal of Practice and Theory, Vol. 9, No. 1, pp. 1-28.

Lou, Y-I. and Wang, M-L. (2009), "Fraud Risk Factor Of The Fraud Triangle Assessing The Likelihood Of Fraudulent Financial Reporting”, Journal of Business and Economics Research, Vol. 7, No. 2, pp. 61-78.

Özkul, F. U. and Pamukçu, A. (2012), "Fraud Detection and Forensic Accounting”, in: C,alıyurt, K. and Idowu, S.O. (Ed.), Emerging Fraud, Springer-Verlag, Berlin, Heidelberg, pp. 19-41.

Pfister, J. A. (2009), Managing Organizational Culture for Effective Internal Control: From Practice to Theory, Physica-Verlag, Berlin, Heidelberg.

Porter, L. W. and Lawler, E. E. (1968), Managerial Attitudes and Performance. Richard D. Irwin, Homewood, IL.

Rae, K. and Subramaniam, N. (2008), “Quality of internal control procedures: Antecedents and moderating effect on organisational justice and employee fraud”, Managerial Auditing Journal, Vol. 23, No. 2, pp. 104-124

Sutherland, E. H. (1949), White-Collar Crime. Dryden Press, New York, NY.

Van Iddekinge, C. H., Roth, P.L., Raymark, P. H. and Odle-Dusseau, H.N. (2012), “The criterion-related validity of integrity tests: An updated meta-analysis”, Journal of Applied Psychology, Vol. 97, No. 3, pp. 499-530.

Vroom, V. H. (1964), Work and Motivation. McGraw-Hill, New York, NY.

Wilks, T. J., and Zimbelman, M. F. (2004), “Decomposition of Fraud-Risk Assessments and Auditors' Sensitivity to Fraud Cues”, Contemporary Accounting Research, Vol. 21, No. 3, pp. 719-745. 


\section{Appendix - copy of the full survey questionnaire used for the pilot study}

\section{PLAIN LANGUAGE STATEMENT AND CONSENT FORM}

\section{INTRODUCTION}

As you know fraud is a major problem for many organisations and we all suffer when individuals are able to successfully defraud an organisation. We are trying to understand why occupational fraud might occur and develop an assessment measure that will help reduce fraud and the subsequent costs to organisations. We believe that your experience in studying fraud will help us in our endeavour.

We have compiled a bibliography of the literature that deals with occupational fraud and we are in the process of analysing the individual elements. However we would like your comments to help to weight the importance of the factors that explain why fraud occurs.

This survey is anonymous, but if you do leave your contact details we will be pleased to keep you posted on progress in this important area of research.

(Please use as much space as required to answer these questions) 


\section{Occupational Fraud}

Definition: Report to the Nation on Occupational Fraud and Abuse," issued by the Association of Certified Fraud Examiners (ACFE) defines occupational fraud as:

"The use of one's occupation for personal enrichment through the deliberate misuse or misapplication of the employing organization's resources or assets"

\section{Question-1}

What is your view on definition of occupational fraud? Is there anything else you would like to add to the definition of occupational fraud?

\section{Question-2}

Have you come across occupational fraud in your organisation?

\section{Question-3}

If yes, what was the size of occupational fraud in your organisation?

- $<\$ 500,000$

- $\$ 500,000$ to $\$ 1,000,000$

- $>\$ 1,000,000$

\section{Question-4}

Does the size of fraud impact the effect of fraud on organisation? Please explain.

\section{Question-5}

What do you think are the most important forms of occupational fraud? In your experience which one is most prevalent?

\section{Causes of Fraud}

Fraud and financial crime have probably existed since the beginning of commerce. People commit fraud for different reasons. 


\section{Question-6}

In your view why do people commit occupational fraud?

\section{Question-7}

Please comment on economic as well as non-economic aspects of motivation

\section{Question-8}

What kinds of situations do you think would serve as opportunities for people to commit fraud?

\section{Question-9}

How do you think the people who commit fraud rationalise what they have done?

\section{Question-10}

Do you think there is a certain personality type or a set of behavioural traits that can signal a higher likelihood of future fraudulent behaviour by an individual employee even if there is no past history?

Can you give an example from your experience or thoughts?

\section{Question-11}

In your view, to what extent can organizational culture determine an employee's actual behaviour?

Can you give an example from your experience or thoughts?

\section{$\underline{\text { Prevention of Fraud }}$}

Prevention is the key to fighting fraud. It is much less expensive to prevent fraud from occurring than to detect and investigate the fraud. 


\section{Question-12}

In your view what should an organisation do WHEN IT IS RECRUITING PEOPLE to the organisation, that will help reduce the potential for occupational fraud?

\section{Question-13}

In your view what should an organisation do WHEN IT IS PROMOTING PEOPLE in the organisation, that will help reduce the potential for occupational fraud?

\section{Question-14}

Are there other strategies related to individuals in the organisation that the organisation should be adopting throughout the year to protect itself from the potential of ongoing fraud?

\section{Question-15}

Has your organisation established a fraud awareness program and fraud reporting mechanism for prevention, detection and reporting of fraud?

\section{Question-16}

Do you think loopholes in internal control mechanisms often or sometimes go unnoticed?

What would be the causes (if so)? Do you have any examples?

\section{Lack of controls/consequences of Fraud}

\section{Question-17}

Do you have examples of 'critical incidents' that have occurred that show the excellence OR weaknesses of the internal systems in operation? (Explain).

\section{Question-18}

What would be good examples of effective management of the risk factors for fraud in organisations? 


\section{Other factors}

\section{Question-19}

Are there particular times when organisations would be more vulnerable to occupational fraud?

\section{Question-20}

Some organisations may be lenient/helpful/sympathetic when a continuing fraud has been uncovered. Can you give examples and also add your views on the possible fall-out from being lenient?

\section{Information on Fraud Triangle}

The best and most widely accepted model for explaining why "good people" commit fraud is the Fraud Triangle. This is a model developed by Dr. Donald Cressey, a criminologist whose research focused on embezzlers, people he called "trust violators".

\section{Question-21}

What do you think are the strengths (and separately, weaknesses) of the fraud triangle model? 